\title{
Vortex Induced Vibrations Analysis Across a Tapered Tower
}

\author{
M Rehan Khan ${ }^{1}$, H. Abbas ${ }^{2}$, Sijal Ahmed ${ }^{3}$ \\ ${ }^{1,2,3}$ Institue of Avionics \& Aeronautics (IAA), Air University, Islamabad
}

\begin{abstract}
In this paper, 3D flow past a long tapered tower is examined. A tapered tower is described by the taper ratio. Tapered cylinders are a good description of many structures, like wind turbine tower e.t.c. Similar to the flow around cylinders, the Reynolds number is the important flow parameter, and the Strouhal number represents the shedding frequency. These flow patterns are difficult to predict and measure experimentally very time dependent nature. The governing Navier-Stokes equations with suitable boundary conditions are solved by using a CFD solver FLUENT (16.0). The computational mesh is created using ICEM. The flow fields are presented by streamline and velocity magnitude. Vortex induced vibration simulations are performed to capture vortex shedding frequency by using lift coefficient Cl data, drag coefficient and dimensionless strouhal number can also be obtained using viv simulation results.
\end{abstract}

Keywords: Tapered, Wind turbine, Shedding Frequency, Strouhal Number

\section{Introduction}

Vortex induced vibrations (VIV) are known to contribute significantly to fatigue damage of wind turbine tower [1]. However, important uncertainties are still present when it comes to methods for calculation of damage for wind turbine towers. The uncertainties are associated to fundamental understanding of vortex induced vibrations in situations where a large number of frequencies may become active. At least four different approaches are today used [2]:

- One frequency is assumed to dominate, and the response is assumed to be harmonic with a fixed amplitude

- The response is assumed to take place at one frequency, but the amplitude is controlled by a low-frequency envelope process

- A number of response frequencies act simultaneously. Each of these frequencies are harmonic, and the phase between the components are random. This approach might be characterized as "concurrent frequencies", or "space sharing" with reference to the definition of excitation zones on the structure without overlaps.

- A number of response frequencies compete in time and dominates consecutively. The response is always assumed to be harmonic, but the frequency will vary from one period of time to the next. This approach is often referred to as "consecutive frequencies" or "time sharing". Excitation zones on the structure may overlap according to this approach.

\section{Simulation Model of the Wind Turbine Tower}

\section{A. CFD and fluid model}

The flow of fluid and transport process is governed by conservation laws i.e. law of conservation of mass, momentum and energy. Conservation laws are work out collectively according to the physic of problem which results in collection of partial differential equations, that resulting equation are governing equations of the flow. The following part consist of the theoretical knowledge of CFD and the method use for this particular case.
B. Mass conservation principle and equation of continuity

The law of conservation of mass is define as that the rate by which mass is increased in a infinitesimal region of the fluid continuum equalizes the total flow of mass into a infinitesimal region of the fluid continuum. By applying this principle to a flow model resulted in a equation called equation of continuity [20]. The equation of continuity for a compressible flow can be written as follows

$$
\frac{\delta P}{\delta t}+\operatorname{div}(\rho u)=0
$$

where u represents flow velocity $\rho$ represents the density.

\section{Motion-induced wind loads}

Structural motion induces a feedback to the air flow generating the cross-wind load on the structure. For flexible structures these motion-induced wind loads are significant. The concept of aero elasticity covering these load contributions is discussed below. Structural motion interacts with the wind field in such a way that the dominating vortex shedding frequency synchronizes with the structure's natural frequency. This phenomenon is called lock-in. Many experiments have been made in order to determine the influence of structural motions on the correlations of the cross-wind loading. The results of these experiments show that increasing vibration amplitudes cause an increase of correlation length. The above-mentioned properties of lockin and motion-dependent correlations are related to the aerodynamic cross-wind loading caused by the structural vibrations.

\section{Different cases of simulation}

Initially, models of both flow and solid domains are established with proper dimensions. Design Modeler is used as a for modeling the geometries. The mesh of fluid domain are generated using ICEM and the finite element mesh is created by ANSYS Meshing. The simulation setup includes necessary steps such as defining the material properties, boundary conditions and solver setup for the three different models. At the end of the simulation setup, the fluid model consists of one mediums (air) the wind passes the wind turbine tower, whereas the structure is a tapper cylinder with 


\section{International Journal of Science and Research (IJSR) \\ ISSN (Online): 2319-7064}

Index Copernicus Value (2013): 6.14 | Impact Factor (2015): 6.391

one ends fixed in ground. A simple sketch of a wind approaching the tapper cylinder is shown in Figure 1.

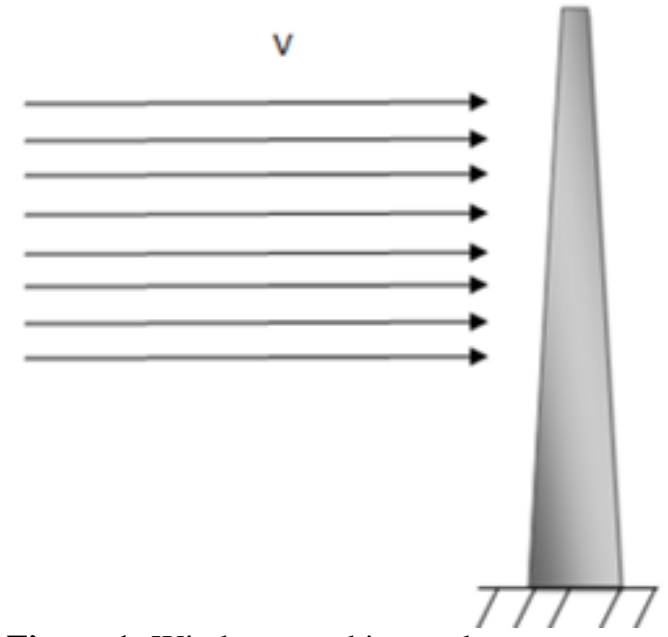

Figure 1: Wind approaching to the tapper tower

These cases are formed by varying the taper angle but keeping the thickness and Young's modulus of the material are same for all case. The following three cases have been finally selected to reach reasonable conclusions from the work.

Table 1: Different cases for VIV Simulations

\begin{tabular}{|c|c|c|c|}
\hline & Length $(\mathrm{m})$ & D Down $(\mathrm{m})$ & D up $(\mathrm{m})$ \\
\hline Case 1 & 69 & 5 & 3 \\
\hline Case 2 & 69 & 4.2 & 2.5 \\
\hline Case 3 & 69 & 3.8 & 2.3 \\
\hline
\end{tabular}

\section{Results and Discussion}

The Fast Fourier Transform (FFT) is implemented to calculate the frequencies spectrum of $f_{v}$ as indicated in Figure shown below. Figure (2 to 10) indicates the result of the measurements of the VIV simulation by varying taper angle of wind turbine tower at wind speed $\mathrm{V}=14,12,10 \mathrm{~m} / \mathrm{s}$. According to the VIV simulations, it was found that the peak vortex shedding frequency is $(0.833 \mathrm{~Hz})$ at $\mathrm{V}=14$ $\mathrm{m} / \mathrm{s}$..Similarly from (Figure 5,6,7), it was found that the peak vortex shedding frequency is $(1.33 \mathrm{~Hz})$ at $\mathrm{V}=14 \mathrm{~m} / \mathrm{s}$ and from (Figure 8,9,10), it was found that the peak vortex shedding frequency is $(1.714 \mathrm{~Hz})$ at $\mathrm{V}=12 \mathrm{~m} / \mathrm{s}$.

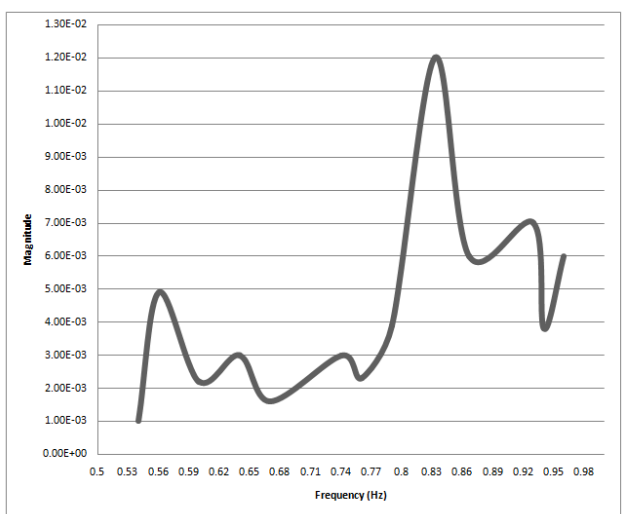

Figure 2: Frequency vs. Magnitude at V=14m/s (case 1)

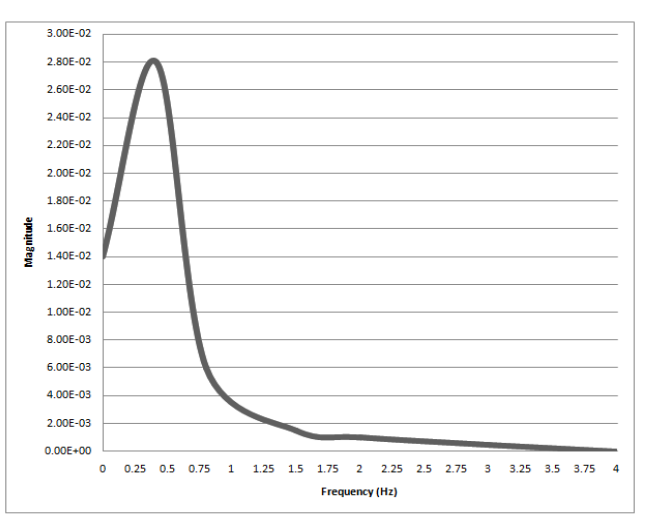

Figure 3: Frequency vs. Magnitude at V=12m/s (case 1)

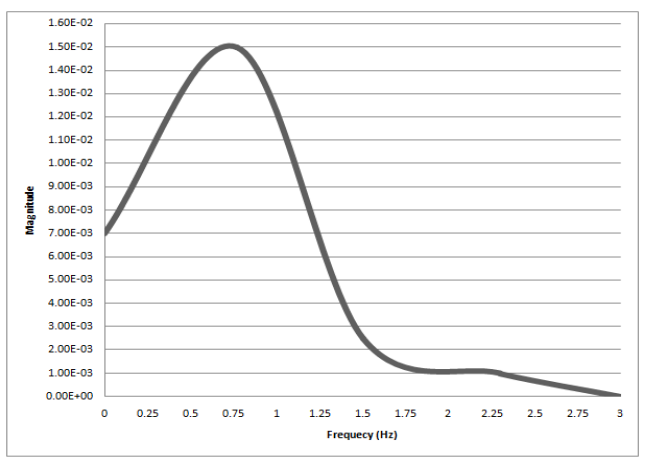

Figure 4: Frequency vs. Magnitude at V=10m/s (case 1)



Figure 5: Frequency vs. Magnitude at $V=14 \mathrm{~m} / \mathrm{s}$ (case 2)

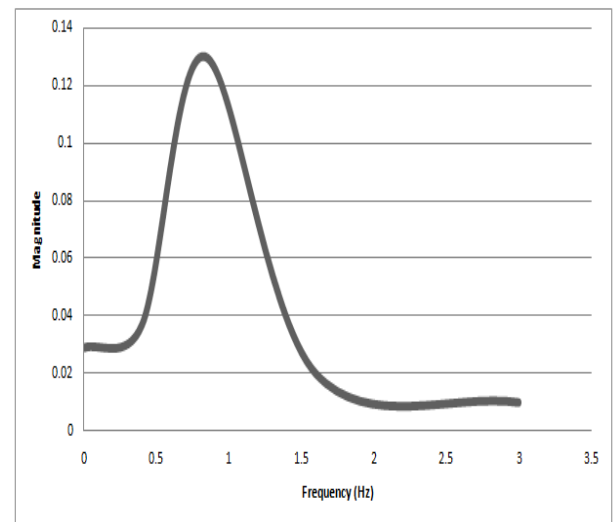

Figure 6: Frequency vs. Magnitude at V=12m/s (case 2)

Volume 5 Issue 6, June 2016 www.ijsr.net 


\section{International Journal of Science and Research (IJSR) \\ ISSN (Online): 2319-7064}

Index Copernicus Value (2013): 6.14 | Impact Factor (2015): 6.391

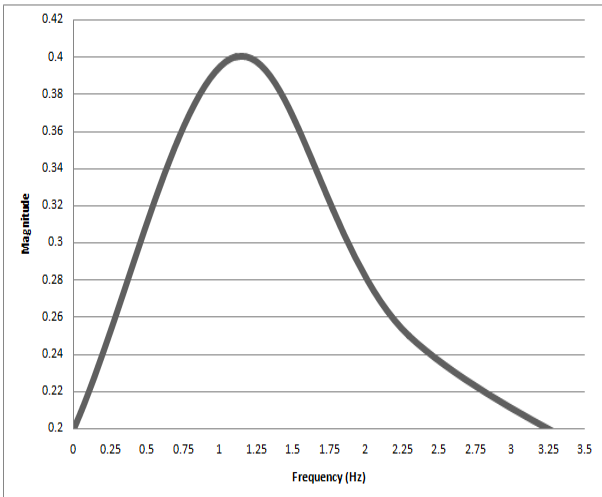

Figure 7: Frequency vs. Magnitude at V=10m/s (case 2)

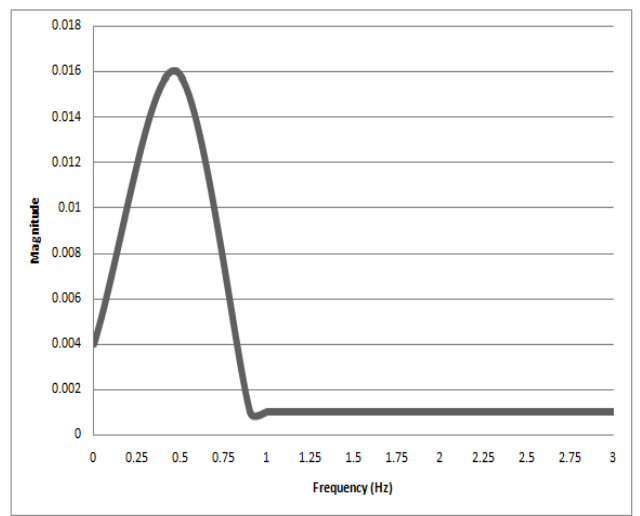

Figure 8: Frequency vs. Magnitude at $\mathrm{V}=14 \mathrm{~m} / \mathrm{s}$ (case 3)

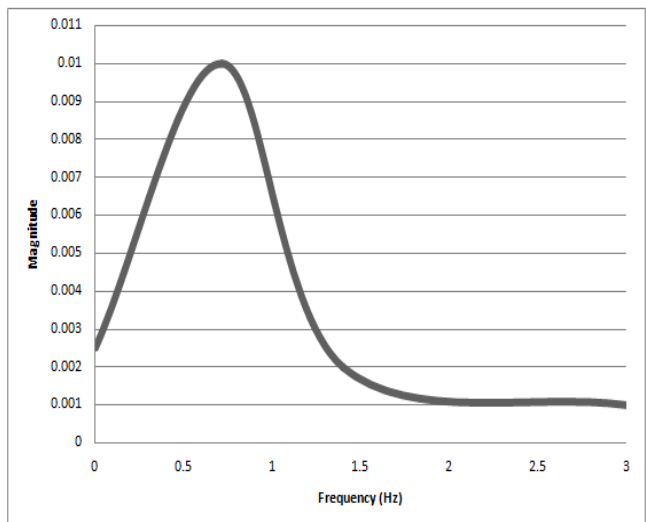

Figure 9: Frequency vs. Magnitude at $\mathrm{V}=12 \mathrm{~m} / \mathrm{s}$ (case 3)

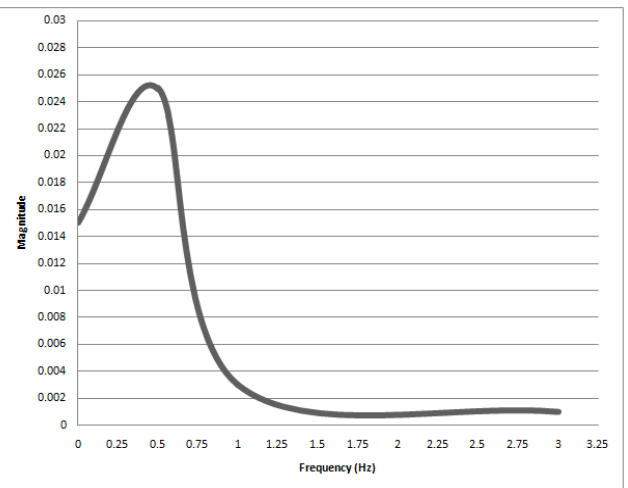

Figure 10: Frequency vs. Magnitude at V=10 m/s (case 3)

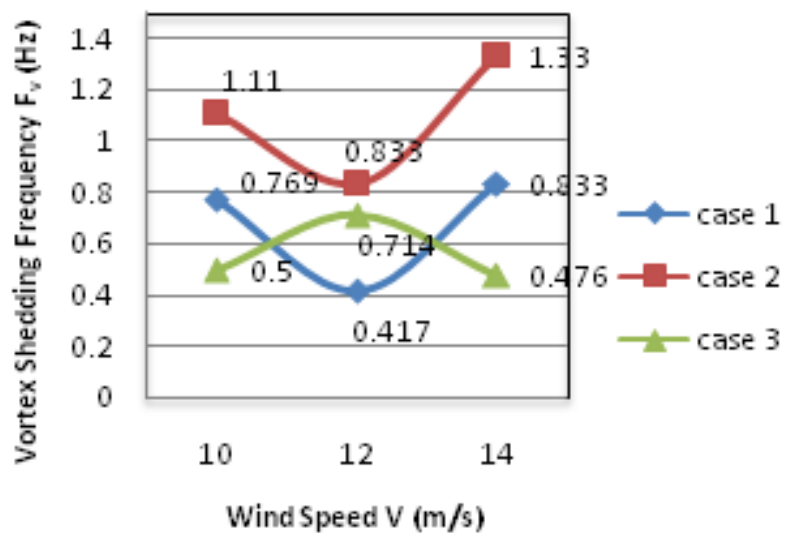

Figure 11: Vortex Shedding Frequency Fv (Hz) Vs Wind Speed

\section{Conclusion}

The CFD analysis has been carried out on tapper tower to understand the vortex induced vibration behavior by varying tapper angle but keeping the tapper ratio same. As from VIV simulation results shown in figure 11 it can be observed that for case 1 the peak vortex shedding frequency can be seen for $\mathrm{V}=14 \mathrm{~m} / \mathrm{s}$ and for case 2 the peak vortex shedding frequency will be observed for $\mathrm{V}=14 \mathrm{~m} / \mathrm{s}$ but for case 3 peak vortex shedding frequency will be at $\mathrm{V}=12 \mathrm{~m} / \mathrm{s}$.So from these simulation results it can be concluded that if tapper angle will be decreased than vortex will dislocate at $\mathrm{V}=14$ $\mathrm{m} / \mathrm{s}$ results in decrease in shedding frequency. These analysis are helpful for further structural simulation as from these analysis we get better understanding about peak vortex shedding cases and further analysis can be done to capture the response of the structure due to wind loads.

\section{References}

[1] Theodor krauthammer "A Numerical Study Of Windinduced tower vibrations", computer and structure volume 26,pp 233-241,1987

[2] F.J. Huera-Huartea, P.W.Bearman "Wake structures and vortex-induced vibrations of along flexible cylinder" Journal of Fluids and Structures 25,(2009)991-1006

[3] K. Lam ,, F. H. Wang , J.Y. Li , R.M.C. So "Experimental investigation of the mean and fluctuating forces of wavy (varicose) cylinders in a cross-flow" Journal of Fluids and Structures 19 (2004) 321-334

[4] Amit Dhiman and Mudassir Hasan "CFD Analysis of the Steady Flow across a Tapered Trapezoidal Cylinder" WCE 2010, June 30 - July 2, 2010, London, U.K.

[5] Park and Lee "flow structure around a finite circular cylinder embedded in various atmospehric boundry layer".Fluid dynamic Research 30,197-215

[6] R. D. Richardson, G. M. McNerney, Wind energy system, Proceedings of the IEEE, Vol. 81, Issue 3, 1993 , pp. 378-389.

[7] A. Gaster and A. Mazouzi. "Wind-induced ovalling oscillations of cylindrical shells: Critical onset velocity and mode prediction". Journal of Fluids and Structures, 10(7):691.704, 1996.

[8] MP. Paidoussis, SJ. Price, GI. Fekete, and BG. Newman. Ovalling of chimneys : Induced by vortex 


\section{International Journal of Science and Research (IJSR) \\ ISSN (Online): 2319-7064}

Index Copernicus Value (2013): 6.14 | Impact Factor (2015): 6.391

shedding or self-excited Journal of Wind Engineering and Industrial Aerodynamics, 14(1.3):119. 128, 1983.

[9] Al-Jamal, H. and Dalton, C. Vortex-induced vibrations using large eddy simulation at a moderate Reynolds number. Journal of Fluids and Structures, 19:73-92, 2005.

[10]A. Gasters, P. 1994 Numerical investigation of response and wake characteristics of a vortex-excited cylinder in a uniform stream. Journal of Fluids and Structures 8 (4), 367 - 390. Anagnostopoulos, P. \& Bearman, P. W. 1992 Response characteristics of a vortex-excited cylinder at low reynolds numbers. Journal of Fluids and Structures 6, 39-50.

[11]Bearman, P. W. \& Meneghini, J. R. 2008 Unsteady response of a circular cylinder under wake-induced excitation from a fixed upstream cylinder. In Flowinduced vibration (ed. I. Zoloratev \& J. Hor'a a cek). Prague, Czech Republic.

[12] Assi, G. R. S., Meneghini, J. R., Aranha, J. A. P., Bearman, P. W. \& Casaprima, E. 2006 "Experimental investigation of flow-induced vibration interference between two circular cylinders". Journal of Fluids and Structures 22, 819-827.

[13] Barkley, D. 2005 "Confined three-dimensional stability analysis of the cylinder wake". Physical Review E 71 (1), 017301.

[14] Tan Jiqiu, Zhong Dingqing, Wang Qiong "Modal Analysis on Fluid-Structure Interaction of MW-Level Vertical Axis Wind Turbine Tower. Sensors \& Transducer"

[15] Hani M. Negma, Karam Y. Maalawib,* "Structural design optimization of wind turbine towers" Computers and Structures 74 (2000) 649-666

\section{Author Profile}

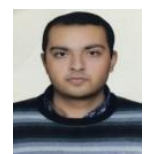

Mr. M.Rehan Khan M.S., is currently working as a Lab Engineer in the Department of Mechanical and Aerospace Engineering at Air University, Islamabad Pakistan. He has about three years of teaching experience. His areas of specializations are Computational Fluid dynamics and thermal engineering.

Volume 5 Issue 6, June 2016 www.ijsr.net 